\title{
A simple and sensitive flow cytometric assay for the determination of the cytotoxic activity of human natural killer cells
}

\author{
Katarina Radošević, Henk S.P. Garritsen, Marja Van Graft, Bart G. De Grooth and Jan Greve \\ Department of Applied Physics, Twente University of Technology, 7500 AE Enschede, The Netherlands
}

(Received 8 May 1990, revised received 29 June 1990, accepted 31 August 1990)

\begin{abstract}
A new, simple and sensitive flow cytometric assay for the determination of the cytotoxic activity of human natural killer cells is described. The assay is based on the use of two fluorochromes. The target cell population is stained with one fluorochrome (octadecylamine-fluorescein isothiocyanate, F-18) prior to incubation with the effector cells. F-18 remains in the membrane of the target cells even when they are killed thereby permitting a clear separation between effector and target cells. Dead cells are determined by staining with a second fluorochrome (propidium iodide) after incubation of effector and target cells.

F-18 is not toxic and does not decrease the cytotoxic activity of human natural killer cells. It is also stable (exchange between labeled and non-labeled cells is negligible in a period of at least $4 \mathrm{~h}$ at $37^{\circ} \mathrm{C}$ ) and it remains in the membrane of the killed cells. A clear distinction between unlabeled effector and labeled target cells is obtained, even after incubation of target and effector cells for $4 \mathrm{~h}$ at $37^{\circ} \mathrm{C}$ and using a high effector cell-target cell ratio $(75: 1)$. A good correlation with the ${ }^{51} \mathrm{Cr}$ release assay was obtained.

A potential application of the flow cytometric cytotoxicity assay using whole blood instead of isolated lymphocytes is presented.
\end{abstract}

Key words: Natural killer; Cytotoxicity; Flow cytometry; Octadecylamine-fluorescein isothiocyanate; Propidium iodide

\section{Introduction}

NK cells play an important role in numerous protective and regulatory mechanisms in humans (Trinchieri and Perrusia, 1984; Brooks, 1986; Reynolds and Wards, 1986). The most prominent functional characteristic of NK cells is a spontaneous cytotoxic activity in vitro against a variety

Correspondence to: K. Radoševic, Department of Applied Physics, Twente University of Technology, 7500 AE Enschede, The Netherlands.

Abbreviations: CM, complete medium; FITC, fluorescein isothiocyanate; F-18, octadecylamine-fluorescein isothiocyanate; NK, natural killer; PBL, peripheral blood lymphocytes; PI, propidium iodide. of tumor cells, virus infected cells and clonogenic cells. The most commonly used assay for monitoring the cytotoxic activity of NK cells is the ${ }^{51} \mathrm{Cr}$ release assay (Brunner et al., 1968). Although it is widely used, the ${ }^{51} \mathrm{Cr}$ release assay has numerous disadvantages (use of a radioactive isotope, relatively high spontaneous release of ${ }^{51} \mathrm{Cr}$, influence of ${ }^{51} \mathrm{Cr}$ on the effector cells, problems with labeling certain types of cells, high cost, and the prolonged assay time) (McGinnes et al., 1986; Pross et al., 1986; Reynolds and Wards, 1986; Shi et al., 1987; Papa et al., 1988; Slezak and Horan, 1989; Volgmann et al., 1989). Therefore attempts have been made to develop a flow cytometric cytotoxicity assay which would overcome the disadvantages of the ${ }^{51} \mathrm{Cr}$ release assay and permit a better 
determination of the cytotoxic activity. However, although several flow cytometric cytotoxicity assays have been reported, there are still difficulties distinguishing between target and effector cell populations which is a necessary prerequisite for a precise determination of the cytotoxic activity. The most commonly encountered problems in the flow cytometric cytotoxicity assays are the overlap between the light scatter signals of effector and target cells (Shi et al., 1987; Papa et al., 1988; Vitale et al., 1989) and/or spontaneous leaking of the fluorescent marker, used to determine cytotoxic activity, out of the cells (McGinnes et al., 1986; Alamartine et al., 1989).

Here we report a new and sensitive flow cytometric cytotoxicity assay based on the use of two fluorescent probes: F-18 and PI. F-18 is a membrane probe which has been used for the selection of hybrid hybridomas by means of the flow cytometer (Koolwijk et al., 1988). In our cytotoxicity assay we have used F-18 to distinguish between effector and target cells. Target cells are labeled with F-18 prior to incubation with effector cells. After incubation PI is added to identify dead cells. In this way a clear separation between four cell populations is obtained: live target cells, dead target cells, live effector cells and dead effector cells. This ensures not only a more precise determination of cytotoxic activity but also gives additional information about the actual ratio between effector and target cells and the conditions of the effector and target cell population.

\section{Materials and methods}

\section{Cells}

K562 cells were used as target cells. Cells were maintained in continuous suspension culture at $37^{\circ} \mathrm{C}$, in a $5 \% \mathrm{CO}_{2}$ incubator. Iscove's modified Dulbecco's medium (Gibco, U.S.A.), buffered with $25 \mathrm{mM}$ Hepes (Serva, U.S.A.) and supplemented with $10 \%$ heat-inactivated fetal calf serum (Gibco, U.S.A.), $2 \mathrm{mM}$ L-glutamine (Sigma, U.S.A.) and $3.024 \mathrm{~g} / 1 \mathrm{NaHCO}_{3}$, was used as culture medium. Effector cells, PBL, were isolated as previously described (Terstappen et al., 1986). To remove the monocytes, the cell suspension was incubated in a culture flask at $37^{\circ} \mathrm{C}$ in $5 \% \mathrm{CO}_{2}$ for $1 \mathrm{~h}$. Non- adherent cells were collected and resuspended in RPMI 1640 (Gibco, U.S.A.) + Hepes + 10\% fetal calf serum $+2 \mathrm{mM}$ L-glutamine + antibiotics $(100$ IU penicillin-G $+100 \mu \mathrm{g}$ streptomycin-sulfate $/ \mathrm{ml}$ (Sigma, U.S.A.)) (further referred to as a complete medium, CM) at the desired concentration.

\section{Staining procedures}

K562 cells were resuspended in CM at a concentration of $10^{6} / \mathrm{ml}$. F-18 (a generous gift from Pieter Koolwijk, University of Utrecht, The Netherlands) was added to the cell suspension at a final concentration of $0.010-0.025 \mu \mathrm{g} / \mathrm{ml}$. For the cytotoxicity assay a F-18 concentration with an absorbance of 0.140 at $506 \mathrm{~nm}(\sim 0.015 \mu \mathrm{g} \mathrm{F}$ $18 / \mathrm{ml}$ ) (Koolwijk et al., 1988) was used. The cell suspension was incubated in the dark, at $37^{\circ} \mathrm{C}$ in $5 \% \mathrm{CO}_{2}$ for $1-2 \mathrm{~h}$ and was occasionally mixed. After incubation the cells were washed two times with an excess volume of cold $\mathrm{CM}$ and resuspended in CM at a concentration of $10^{5} / \mathrm{ml}$.

Propidium iodide (PI) stock solution was prepared by dissolving $0.01 \mathrm{mg}$ of propidium iodide in $1 \mathrm{ml} \mathrm{10 \%} \mathrm{ethanol.} \mathrm{Stock} \mathrm{solution} \mathrm{was} \mathrm{added} \mathrm{to}$ the cell suspension to a final concentration of 0.1 $\mu \mathrm{g} / \mathrm{ml}$. After $1 \mathrm{~min}$ of gently shaking a double volume of PBS was added. The suspension was gently mixed and immediately analyzed.

\section{Flow cytometer}

Experiments were performed with an 'in house' flow cytometer equipped with a $100 \mathrm{~mW}$ argon ion laser (model 5500A, Ion Laser Technology, Salt Lake City, U.S.A.) tuned to $488 \mathrm{~nm}$ and operated at $50 \mathrm{~mW}$. The instrument is comparable to commercially available machines and has been described elsewhere (Terstappen et al., 1986). To measure the fluorescence a $555 \mathrm{~nm}$ dichroic long pass filter was used in combination with a KV $520-$ OG $530 \mathrm{~nm}$ colour glass filter for the F-18 fluorescence and a RG 645-2 nm colour glass filter for the propidium iodide fluorescence. Fluorescence signals were collected in log mode. At least 8000 cells were measured in each flow cytometric sample.

\section{Flow cytometric cytotoxicity assay}

Target cells (K562) were stained with F-18 and resuspended in $\mathrm{CM}$ at a concentration of $10^{5} / \mathrm{ml}$. 
Effector cells (PBL) were resuspended in $\mathrm{CM}$ at concentrations of $2.5,5.0$ and $7.5 \times 10^{6} / \mathrm{ml}$. Of each effector cell suspension $0.1 \mathrm{ml}$ was mixed with $0.1 \mathrm{ml}$ of target cell suspension. In that way effector cell-target cell ratios of $25: 1,50: 1$ and $75: 1$ were obtained. Each sample was analyzed in triplicate. Control samples consisted of target cells in $\mathrm{CM}$ alone. Samples were centrifuged for $5 \mathrm{~min}$ at $200 \times \mathrm{g}$ and incubated at $37^{\circ} \mathrm{C}$ in $5 \% \mathrm{CO}_{2}$ for 3-4 h. After incubation, samples were placed on ice until the flow cytometric analysis was performed. Immediately before the measurements the samples were stained with PI. The results were analyzed by setting gates on the F-18 and PI fluorescence channels, respectively. The percentage of cytotoxicity was calculated as follows:

$(($ cont - test $) /$ cont $) \times 100=\%$ cytotoxicity

- cont $=$ number of $\mathrm{F}-18$ positive, PI negative cells (= live K562 cells) divided by total num-
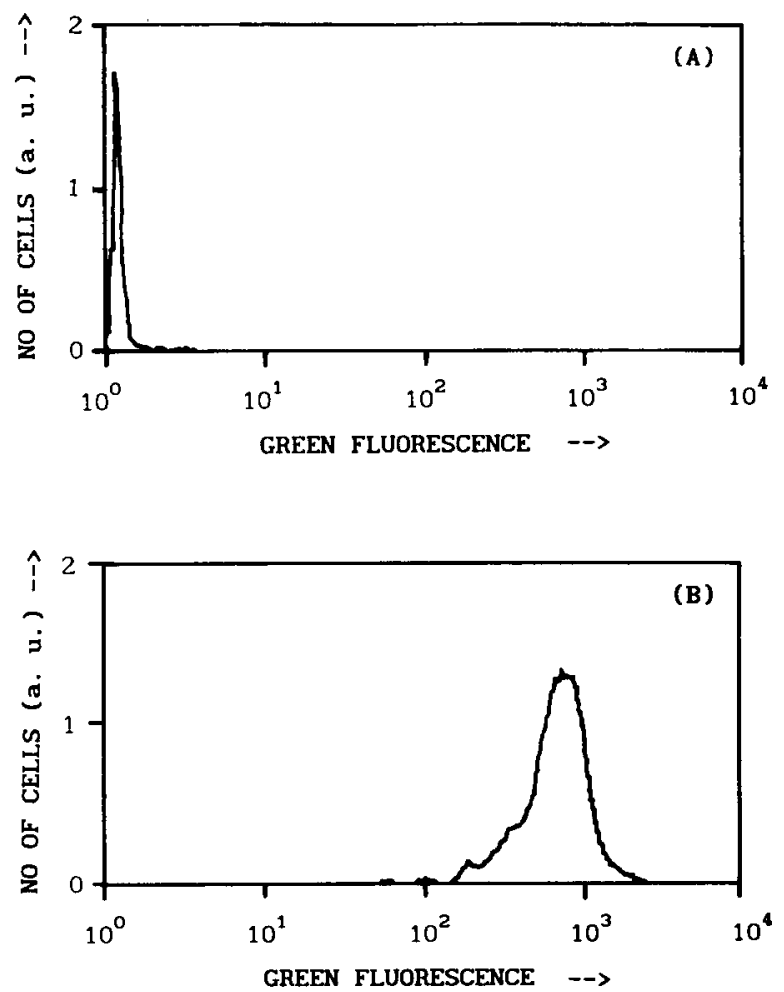

ber of F-18 positive cells (= total number of $\mathrm{K} 562$ cells) in the control sample.

- test $=$ number of $\mathrm{F}-18$ positive, $\mathrm{PI}$ negative cells (= live K562 cells) divided by total number of F-18 positive cells ( $=$ total number of $\mathrm{K} 562$ cells) in the test sample.

In order to measure statistically reliable numbers of target cells, at least $8000 \mathrm{~F}-18$ positive cells ( $=$ target cells) were measured.

\section{${ }^{51}$ Cr-release cytotoxicity assay}

Target cells (concentration $10^{6} / \mathrm{ml}$ ) were incubated with $100 \mu \mathrm{Ci}$ of sodium $\left[{ }^{51} \mathrm{Cr}\right]$ chromate $/ \mathrm{ml} \mathrm{PBS}$ for $1 \mathrm{~h}$ at $37^{\circ} \mathrm{C}$ in $5 \% \mathrm{CO}_{2}$. In the experiment in which the effect of F-18 on the cytotoxic activity was investigated, target cells were incubated with chromium and F-18 simultaneously. Labeled cells were washed two times with PBS, once with CM and then resuspended in CM at a concentration of $10^{5} / \mathrm{ml} \mathrm{CM}$.
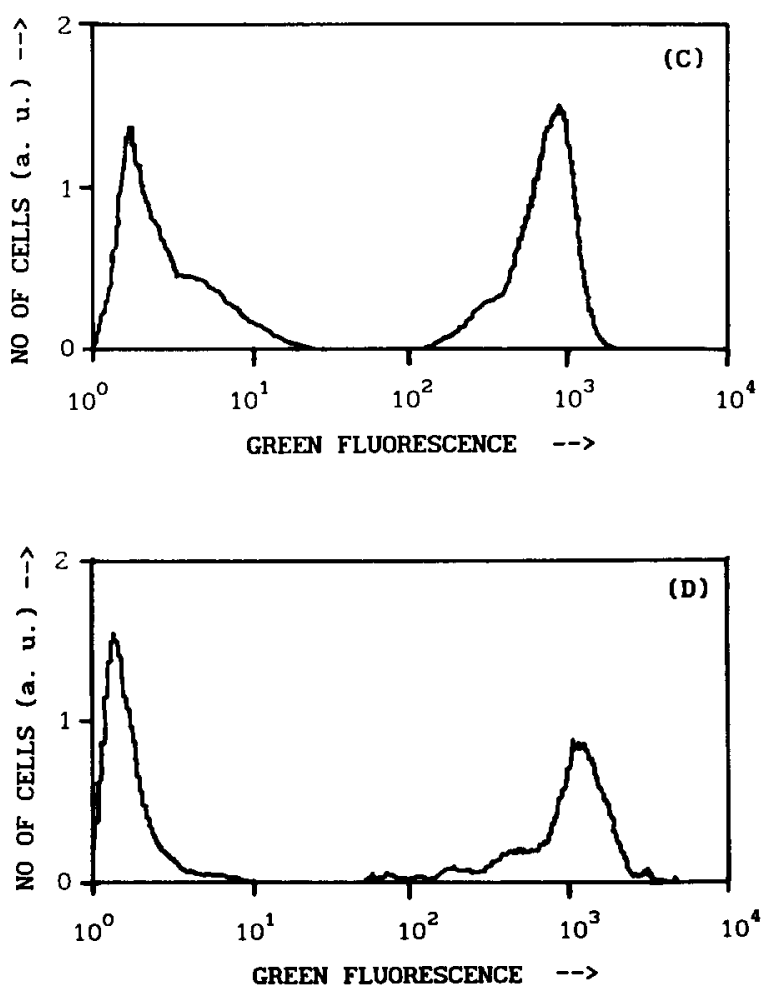

Fig. 1. F-18 labeling of K562 cells. Fluorescence histograms (cell number vs. log fluorescence intensity) of unlabeled K562 cells ( $A$ ), F-18 labeled K562 cells $(B)$ and mixtures of unlabeled and F-18 labeled K562 cells (ratios $1: 1(C)$ and $20: 1(D)$ ) incubated together at $37^{\circ} \mathrm{C}$ for $4 \mathrm{~h}$. 
$0.1 \mathrm{ml}$ of the target cell suspension was mixed with $0.1 \mathrm{ml}$ of appropriate effector cell suspension (concentrations $2.5,5.0,7.5 \times 10^{6} / \mathrm{ml}$, respectively) in a 96 well round bottom plate. Control wells for spontaneous release of chromium contained $0.1 \mathrm{ml}$ of labeled target cells mixed with 0.1 $\mathrm{ml} \mathrm{CM}$. Triplicate samples for every effector cell- target cell ratio were prepared. Samples were centrifuged for $5 \mathrm{~min}$ at $200 \times \mathrm{g}$ and incubated at $37^{\circ} \mathrm{C}$ in $5 \% \mathrm{CO}_{2}$ for $3-4 \mathrm{~h}$. For maximum release of chromium, target cells were lysed by adding 0.1 $\mathrm{ml}$ of $1 \%$ saponin in RPMI to $0.1 \mathrm{ml}$ of cell suspension at the end of the assay. $0.1 \mathrm{ml}$ of the supernatant from each well was removed and the
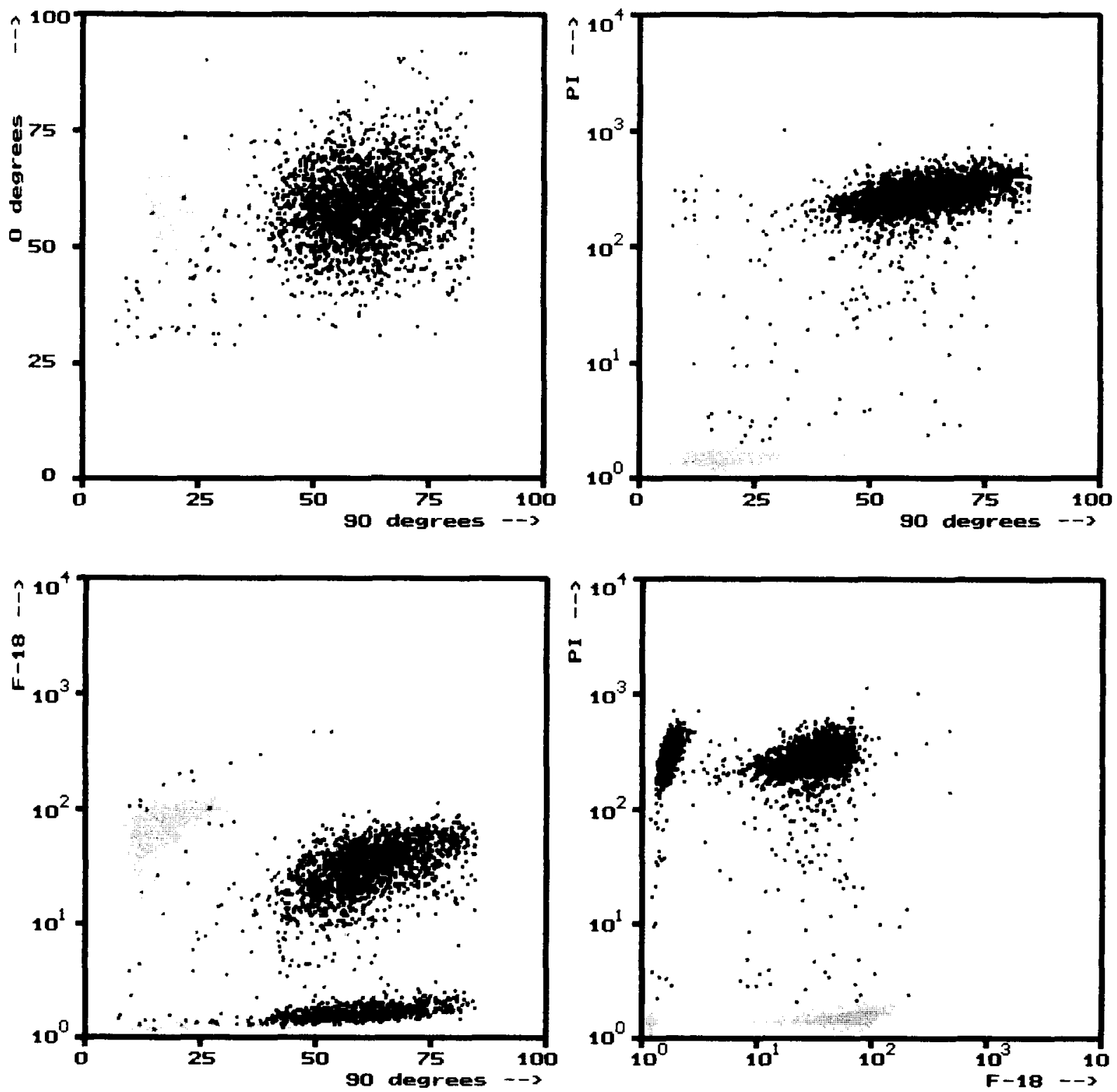

Fig. 2. Mixture of heat treated F-18 labeled K562 cells, untreated F-18 labeled K562 cells, heat treated unlabeled K562 cells and untreated unlabeled K562 cells, stained with PI. Killed F-18 labeled K562 cells remain positive for F-18 fluorescence. There is a good separation between stained and unstained cells for both fluorochromes. 
released chromium was determined using an LKB multi $\gamma 1260$ counter. The percentage of cytotoxicity was calculated as follows:

$(($ cpm exp-cpm spont $) /($ cpm max - cpm spont $)) \times 100$

$=\%$ cytotoxicity

\section{Results}

Our aim has been to develop a cytotoxicity assay in which all target cells (live and dead) could be positively identified, even in the presence of a large excess of effector cells. Attempts to obtain this just on the basis of forward and orthogonal light scattering signals failed because of a small but significant overlap between the signals of human NK cells (dead/live) and K562 target cells (dead/live).

Therefore, we have investigated the possibility of using a fluorescent dye to label the target cells before incubation with effector cells. This dye should not leak out of the cells (whether dead or alive) during the $37^{\circ} \mathrm{C}$ incubation for at least $4 \mathrm{~h}$

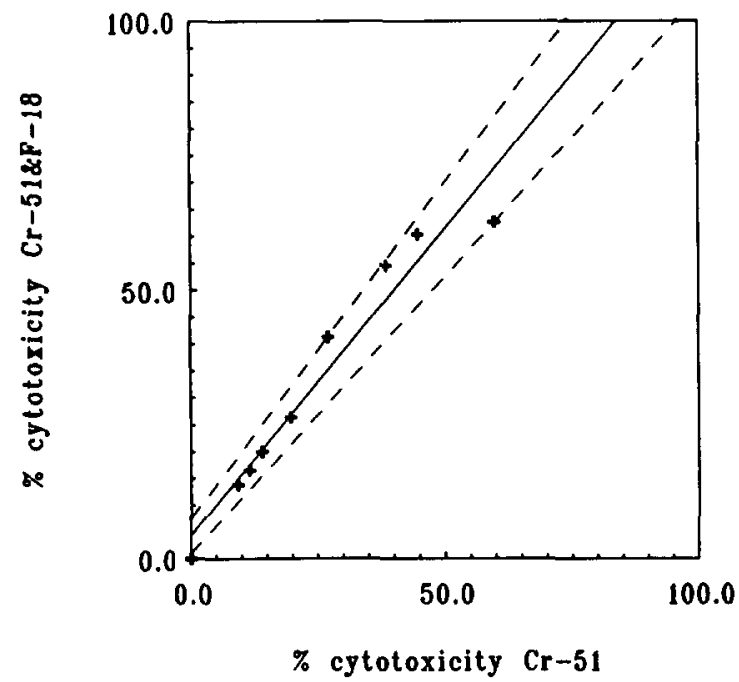

Fig. 3. Correlation of ${ }^{51} \mathrm{Cr}$ release assays using $\mathrm{K} 562$ target cells labeled with ${ }^{51} \mathrm{Cr}$ and ${ }^{51} \mathrm{Cr}+\mathrm{F}-18$, respectively. Effector cells (PBL) isolated from three donors, were incubated with K562 cells for $3 \mathrm{~h}$ (ratios $25: 1$ and 50:1 for all three donors, ratio $75: 1$ for two donors). Each dot represents the mean value of the results of three measurements. Correlation coefficient $=$ 0.97 . and should be suitable for use in combination with dead/live stain. For identification of dead cells we have chosen PI and for labeling the target cells we have investigated several dyes (acridine orange, BCECF-AM, LDS-751). These showed a large leaking out of the cells and/or could not be used in combination with PI because of spectral overlap. We found that F-18 fulfilled our demands since it was incorporated into K562 cells quickly $\left(1-2 \mathrm{~h}\right.$ at $\left.37^{\circ} \mathrm{C}\right)$ and remained in the cell membrane during an incubation period of at least $4 \mathrm{~h}$ at $37^{\circ} \mathrm{C}$. Also, a good separation of the signals of labeled and non-labeled cells, incubated together at $37^{\circ} \mathrm{C}$ for $4 \mathrm{~h}$, was obtained for all concentrations of F-18 used for labeling $(0.01-0.03 \mu \mathrm{g} / \mathrm{ml})$.

Fluorescence histograms of unlabeled and F-18 labeled K562 cells $(0.015 \mu \mathrm{g} \mathrm{F}-18 / \mathrm{ml})$ are shown in Figs. $1 \mathrm{~A}$ and $1 \mathrm{~B}$, respectively. Labeled and unlabeled cells were mixed together in the ratios $1: 1$ and $1: 20$ and incubated at $37^{\circ} \mathrm{C}$ for $4 \mathrm{~h}$. Flow cytometric analysis of these mixtures are shown in Figs. 1C and 1D, respectively. It is clear that only a very small exchange of F-18 between labeled and unlabeled cells takes place since there is no overlap between the signals of the two populations. Since in our application dead target cells must retain F-18, it was necessary to investigate whether dead cells lose F-18 previously incorporated in their membrane. For that reason, K562 cells stained with F-18 were incubated at $60^{\circ} \mathrm{C}$ for $30 \mathrm{~min}$. Flow cytometric analysis of PI stained sample showed that the heat treatment killed more than $95 \%$ of K562 cells and that they remained positive for the F-18 fluorescence. The results presented in Fig. 2 were obtained by measuring the PI stained mixture of heat treated F-18 stained cells, non-treated F-18-stained cells, heat-treated non-stained cells and non-treated non-stained cells. It can be seen that dead cells remained positive for the F-18 fluorescence and a good separation was obtained between positive and negative cells for both fluorochromes. Although F-18 does not affect the viability of the cells up to $1 \mu \mathrm{g} / \mathrm{ml}$ (Koolwijk et al., 1988), it is not known whether the presence of F-18 in the membrane of the target cells can influence the cytotoxic efficiency of NK cells. To investigate this possibility, we performed a series of ${ }^{51} \mathrm{Cr}$ release cytotoxicity assays using unlabeled and F-18-labeled 

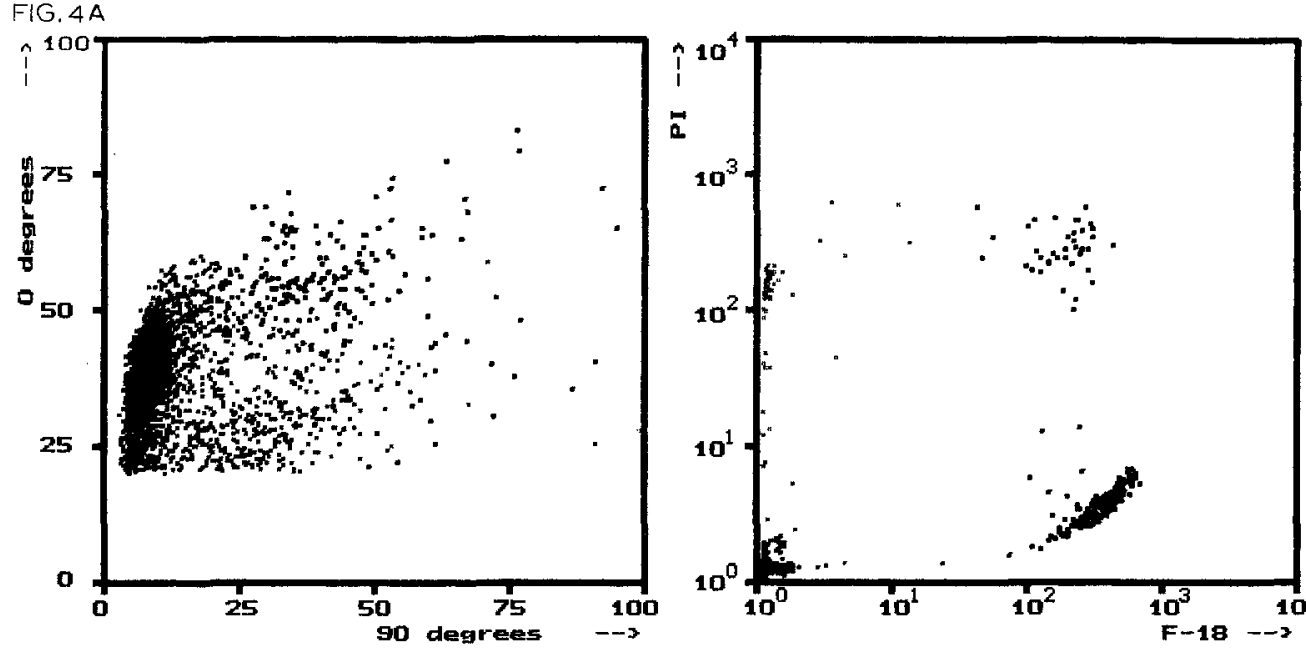

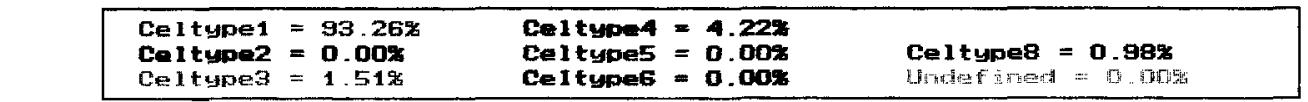
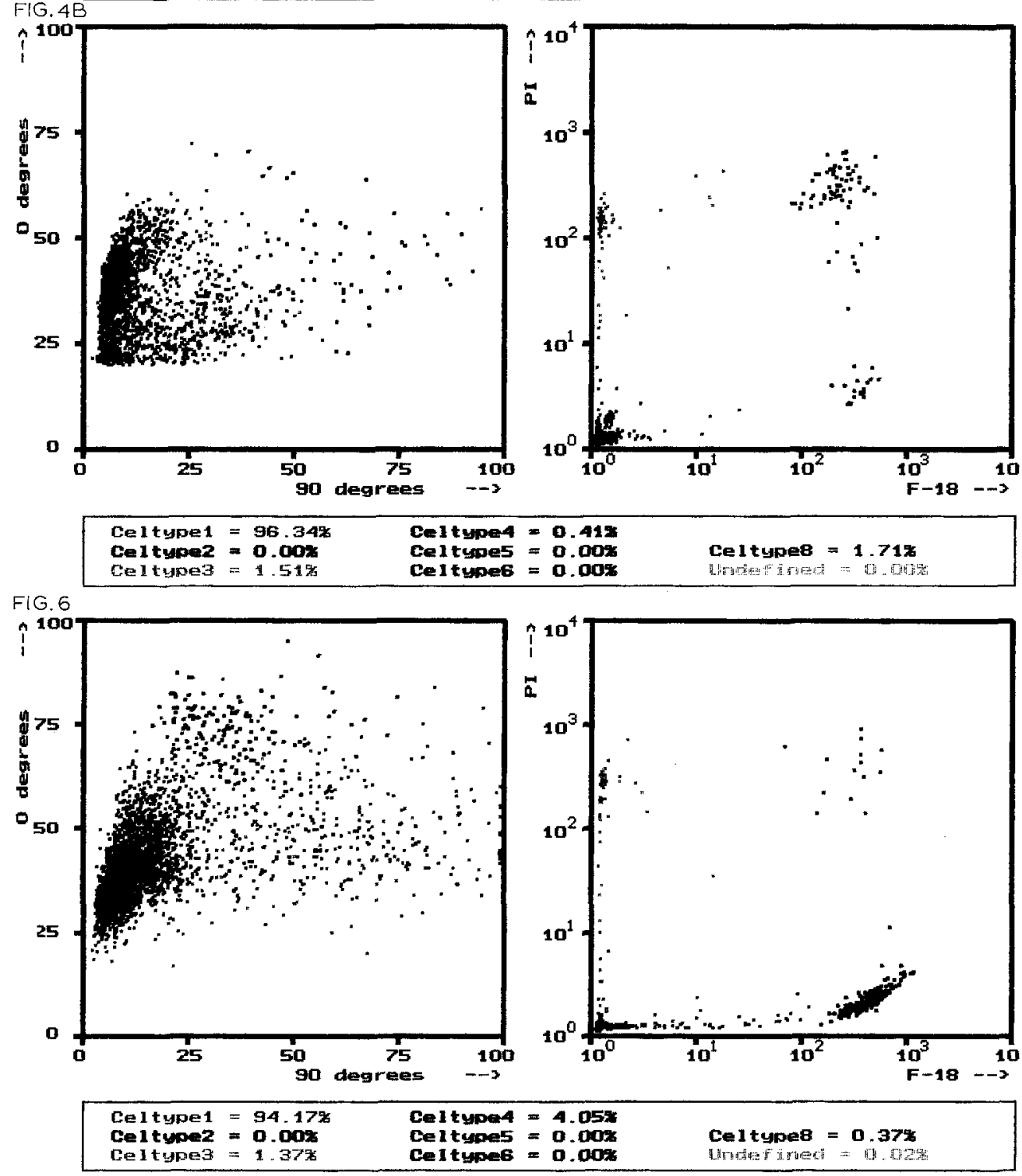


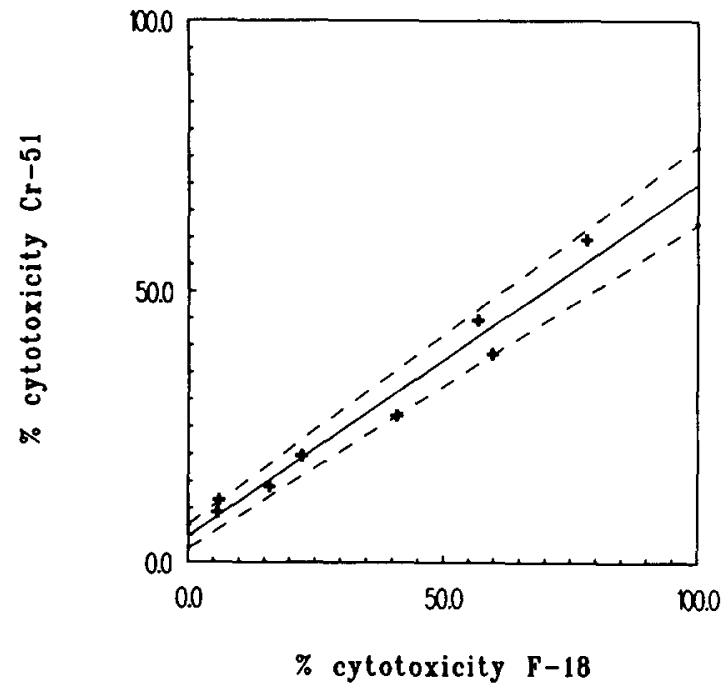

Fig. 5. Correlation of ${ }^{51} \mathrm{Cr}$ release and flow cytometric cytotoxicity assays. Effector cells (PBL) isolated from three donors, were incubated with K562 cells for $3 \mathrm{~h}$ (ratios 25:1 and 50:1 for all three donors, ratio $75: 1$ for two donors). Each dot represents the mean value of the results of three measurements. Correlation coefficient $=0.98$.

K562 cells as targets. The results shown in Fig. 3 indicate that the presence of F-18 in the membrane of the target cells does not decrease the cytotoxic activity of human NK cells.

From these experiments we conclude that F-18 can be used to discriminate K562 target cells, both live and dead, from effector cells in the flow cytometric cytotoxicity assay.

A typical result of the F-18 flow cytometric cytotoxicity assay is shown in Fig. 4. It can be seen that four populations are clearly separated: live K562 (celtype 4, red), dead K562 (celtype 8, black), live lymphocytes (celtype 1, blue), and dead lymphocytes (celtype 3 , green). Such a separation can be obtained with a ratio between effector and target cells as high as $75: 1$. The difference in the number of live target cells in the control sample (target cells incubated alone) and the test sample (target cells incubated with effector cells) reveals the cytotoxic activity. In order to obtain a statistically reliable result, at least 8000 F-18 positive cells (target cells) were measured. We have performed a series of experiments in order to compare the ${ }^{51} \mathrm{Cr}$ release assay with the F-18 flow cytometric assay. Cytotoxic activity of PBL isolated from different donors was determined with the ${ }^{51} \mathrm{Cr}$ release and the flow cytometric assay. Effector cells were incubated for $3 \mathrm{~h}$ with target cells in ratios $25: 1,50: 1$ and $75: 1$ and the cytotoxicity was determined. A comparison of the results of the ${ }^{51} \mathrm{Cr}$ release and flow cytometric cytotoxicity assays for three donors is illustrated in Fig. 5. Similar results were obtained in the other experiments.

We have investigated the possibility of using the F-18 flow cytometric cytotoxicity assay with whole blood instead of isolated lymphocytes. For that purpose heparinized venous blood was mixed with F-18 labeled K562 cells and incubated for 3 $\mathrm{h}$ at $37^{\circ} \mathrm{C}$. Afterwards, PI was added and the samples analyzed in the flow cytometer. These results are shown in Fig. 6. It can be seen that four cell populations are clearly separated: live K562 (celtype 4, red), dead K562 (celtype 8, black), live blood cells (celtype 1, blue) and dead blood cells (celtype 3 , green).

\section{Discussion}

The most common used assay for the determination of NK cell cytotoxic activity is the ${ }^{51} \mathrm{Cr}$ release assay (Brunner et al., 1968). However, although the assay can give useful information concerning the lytic activity of NK cells and susceptibility of different types of target cells to lysis, it suffers from a number of important disadvantages. The absence of information at the single cell level can be considered as one of them and

Fig. 4. Flow cytometric cytotoxicity assay using F-18 and PI. Effector cells (PBL) were incubated with F-18 labeled K562 cells for 3 h. $A$ : ratio $25: 1 ; B$ : ratio $50: 1$.

Fig. 6. Flow cytometric cytotoxicity assay using whole blood. Heparinized venous blood was mixed with F-18 labeled K562 cells and incubated for $3 \mathrm{~h}$. 
flow cytometry offers the possibility of monitoring a cytotoxic process in this manner.

Most of the flow cytometric cytotoxicity assays developed until now employ the scatter characteristics of the cells and one fluorochrome as criteria for determining cytotoxic activity (McGinnes et al., 1986; Shi et al., 1987; Papa et al., 1988; Alamartine et al., 1989; Vitale et al., 1989). On the basis of the decrease in fluorescence intensity of the labeled cells and/or changes in the scatter characteristics of the target cells, which result from the killing process, the cytotoxic activity is determined. However, any precise distinctions between the cell populations is not achieved. Assays based on the different scatter properties suffer from overlap of the cell populations involved in the cytotoxicity process and assays employing one fluorochrome suffer from problems with the relatively high rate of spontaneous leakage of the dye out of the cells. The method we have described here is based on the use of two fluorochromes which permit clear separation of the cell populations. One fluorochrome, F-18, is used for labeling the complete target cell population, prior to incubation with the effector cells. Separation of effector and target cells is possible because F-18 remains in the membrane of the target cells even after they have been killed. In order to identify dead cells we have used a second fluorochrome, PI. Using F-18 in combination with PI it is possible to identify four cell populations: live target cells (cells positive for F-18 and negative for PI), dead target cells (cells positive for F-18 and positive for PI), live effector cells (cells negative for F-18 and negative for PI) and dead effector cells (cells negative for F-18 and positive for PI) (Fig. 4). This yields more information about the cytotoxicity process. As can be seen from Fig. 5 there is a positive correlation between the flow cytometric and the ${ }^{51} \mathrm{Cr}$-release assay.

We have shown that labeling with F-18 is stable (leakage and/or exchange of the fluorochrome between labeled and unlabeled cells in negligible), does not decrease the cytotoxic activity of the human NK cells and can easily be used in the flow cytometric cytotoxicity assay. The concentrations of F-18 we have used for labeling are reported as non toxic (Koolwijk et al., 1988) which is in agreement with our results (data not shown).
Recently Slezak and Horan (1989) have independently developed a flow cytometric cytotoxicity assay based on a similar approach which they applied to the mouse cytotoxic system. The authors have used two fluorochromes (PKH-1 and PI) for the evaluation of the cytotoxic activity of mouse splenic cells against Yac-1 target cells.

Our preliminary results indicate the possibility of using F-18 in the flow cytometric cytotoxicity assay with whole blood instead of isolated lymphocytes (Fig. 6). Besides eliminating the laborious and time consuming lymphocyte isolation procedure, this approach also permits studies of the cytotoxicity process under conditions which are more similar to the in vivo situation. In conclusion, the flow cytometric cytotoxicity assay based on the use of two fluorochromes (F-18 and PI) described here is a simple and sensitive method for the determination of the cytotoxic activity of human NK cells and can easily be used in every laboratory equipped with a flow cytometer.

\section{References}

Alamartine, E., Sabido, O., Buisson, V., Videcocq, C. and Berthoux, F.C. (1989) Carboxyfluorescein diacetate (c'FDA) labelling of K562 and Daudi cells for flow cytometric natural killer cell assay. Poster presented on Third European Cytometry User's Meeting 'Fifteen Years of Cytometry', Dominican Monestry 't Pand, Ghent, Belgium.

Brooks, C.G. (1986) NK cells cloning technology and characteristics of NK cell clones. In: E. Lotzová and R.B. Herberman (Eds.), Immunobiology of Natural Killer Cells, Vol. II. CRC Press, Boca Raton, FL, p. 179.

Brunner, K.T., Mauel, J., Cerottini, J.C. and Chapuis, B. (1968) Quantitative assay of the lytic action of immune lymphoid cells on ${ }^{51} \mathrm{Cr}$-labeled allogenic target cells in vitro; inhibition by isoantibody and by drugs. Immunology 14,181 .

Koolwijk, P., Rozemuller, E., Stad, R.K., De Lau, W.B.M. and Bast, B.J.E.G. (1988) Enrichment and selection of hybrid hybridomas by Percoll density gradient centrifugation and fluorescence-activated cell sorting. Hybridoma 7, 217.

McGinnes, K., Chapman, G., Marks, R. and Penny, R. (1986) A fluorescence NK assay using flow cytometry. J. Immunol. Methods 86, 7 .

Papa, S., Vitale, M., Mariani, A.R., Roda, P., Facchini, A. and Manzoli, F.A. (1988) Natural killer function in flow cytometry. I. Evaluation of NK lytic activity on K562 cell line. J. Immunol. Methods 107, 73.

Pross, H., Callewaert, D. and Rubin, P. (1986) Assays for NK cell cytotoxicity - their values and pitfalls. In: E. Lotzová and R.B. Herberman (Eds.), Immunobiology of Natural 
Killer Cells, Vol. I. CRC Press, Boca Raton, FL, p. 1.

Reynolds, C.W. and Ward, J.M. (1986) Tissue and organ distribution of NK cells. In: E. Lotzová and R.B. Herberman (Eds.), Immunobiology of Natural Killer Cells, Vol. I. CRC Press, Boca Raton, FL, p. 63.

Shi, T.-X., Tong, M.J. and Bohman, R. (1987) The application of flow cytometry in the study of natural killer cell cytotoxicity. Clin. Immunol. Immunopathol. 45, 356.

Slezak, S.E. and Horan, P.K. (1989) Cell mediated cytotoxicity. A highly sensitive and informative flow cytometric assay. J. Immunol. Methods 117, 205.

Terstappen, L.W.M.M., De Groot, B.G., Nolten, G.M.J., Ten Napel, C.H.H., Van Berkel, W. and Greve, J. (1986) Physical discrimination between human $T$ lymphocyte subpopu- lations by means of light scattering, revealing two populations of T8 positive cells. Cytometry 7, 178 .

Trinchieri, G. and Perussia, B. (1984) Biology of disease. Human natural killer cells: biologic and pathologic aspects. Lab. Invest. 50, 489.

Vitale, M., Neri, M., Comani, S., Falcieri, E., Rizzoli, R., Rana, R. and Papa, S. (1989) Natural killer function in flow cytometry. II. Evaluation of NK lytic activity by means of target cell morphological changes detected by right angle light scatter. J. Immunol. Methods 121, 115.

Volgmann, T., Klein-Struckmeier, A. and Mohr, H. (1989) A fluorescence-based assay for quantitation of lymphokineactivated killer cell activity. J. Immunol. Methods 119, 45. 